 \\ International Journal of Social Sciences and Management
}

\section{A Rapid Publishing Journal}

ISSN 2091-2986

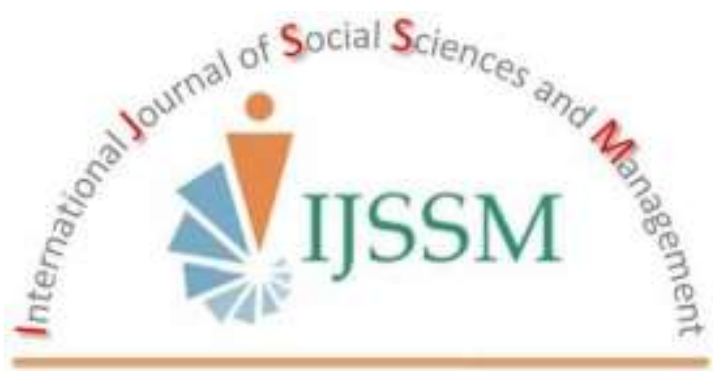

\section{Indexing and Abstracting}

CrossRef, Google Scholar, International Society of Universal Research in Sciences (EyeSource), Journal TOCs, New Jour, Scientific Indexing Services, InfoBase Index, Open Academic Journals Index (OAJI), Scholarsteer, Jour Informatics, Directory of Research Journals Indexing (DRJI), International Society for Research Activity (ISRA): Journal Impact Factor (JIF), Simon Fraser University Library, etc.

Vol- 3(1),January 2016 


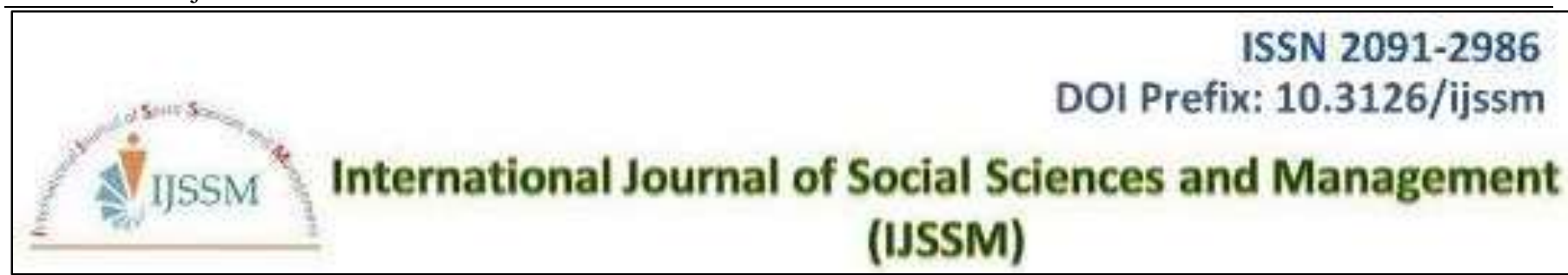

\title{
Research Article \\ EFFECTS OF SUSTAINABLE TOURISM ON SUSTAINABLE COMMUNITY DEVELOPMENT IN COASTAL REGIONS IN THE UNITED KINGDOM
}

\author{
Ramesh Neupane \\ University Village Thapathali Kathmandu Nepal \\ Email: rameshneupane47@yahoo.com
}

\begin{abstract}
The main purpose of this research is to examine the effects of sustainable tourism on sustainable community development in coastal regions in the UK. This research also seeks to investigate the extent of sustainable tourism practices and the extent of sustainable community development practices in the coastal regions in the UK.

The study was conducted by deductive approach cross sectional method following quantitative techniques. The respondents are selected from hotels, restaurants, travel agencies who are operating their business activities in the coastal regions, and the local council of the coastal regions. The questionnaires survey was used to collect primary data from the respondents. The sample of 160 respondents was selected by using convenience sampling technique or on the basis of their availability and interest.

The results indicate that sustainable tourism and sustainable community development are positively and significantly correlated with each other. Similarly, regression analysis shows that sustainable tourism has significant effects on sustainable community development as $\beta=$ 0.804 , and $\mathrm{P}=0.000$ which is less than 0.05 . Also, there is a high level of sustainable tourism and sustainable community development practices in the coastal regions in the UK.
\end{abstract}

Keywords: Sustainable tourism; sustainable community development; coastal regions; environmental management.

\section{Introduction}

Tourism is one of the fastest growing industries in the world and is a main source of generating income for many countries. Tourism also provides millions of jobs as it is a people oriented industry which has revitalised the local economies (Goeldner and Ritchie, 2003). However, tourism can also cause various problems such as ecological degradation, social disorder, loss of cultural heritage, and economic dependence. The study about the effects of tourism has led the alternative forms of tourism such as sustainable tourism which includes ecotourism, naturebased tourism and cultural tourism. The form of alternative tourism such as sustainable tourism is becoming a major mainstream in tourism in most of the developed countries (Ashley, 2000).

The concept of sustainable tourism is about to make a positive differences to the environment and the people of the destination we visit to. The mission of sustainable tourism is to perfect the individual tourism experiences with managing our activities and functions in sustainable way. The view of sustainable tourism has obtained an increased attention in employing available resources at the local area in tourism development along with the view that the associated communities should get benefits such as economic and social opportunities as much as possible (Elper and Halpenny, 2001). Various efforts has been carried out to increase economic benefits from the activities of tourism such as increasing overall expenditures, increasing number of arrivals, and increasing their overall stay. The possibility of tourism for poverty alleviation and sustainable community development is highly recognised by international bodies and national governments (Ali and Frew, 2013). The developing countries in the world continue to focus on opportunities of sustainable community development in the rural areas. These countries can be benefited from the potential gains from primary activities of tourism as a major means of community development, and geographical growth of tourism and the labour intensive nature of tourism can support various development functions along with overall value chain (WTTC, 2010). This is mainly suitable for remote and rural sectors in developing countries as well as rural and coastal areas of the developed countries. However, this research is conducted in the case of welldeveloped coastal regions in the UK. 


\section{Rationale of the Research}

Tourism that focuses on ecological environment has obtained growing concern in tourism industry because of the reality that it could have positive involvement to socioeconomic development and environment protection of the host country (Ko, 2005). Nevertheless, unrestricted tourism growth can also cause destruction of fragile ecosystem, environment hazard, and social and cultural conflicts. It is therefore, sustainable tourism has high significance because it has low effects on local environment, communities and culture (Sharply, 2010). Sustainable tourism also ensures to bring positive experiences to tourists, local communities and tourism companies. Therefore, it has obtained the attention of many scholars in recent years (Liu, 2003).

Moreover, most of existing research focuses on either sustainable tourism practices or sustainable community development separately in different perspectives. This particular research topic has not found studied in coastal regions in the UK. So, the researcher believes that this study will fulfil the gap in the literature. This research seeks how sustainable tourism practices is maintained in the coastal regions, is the tourism development sustainable? And how it is linked to sustainable community development. It is therefore, examining 'the effects of sustainable tourism on sustainable community development' became an issue for research. This research is significant to understand the extent of sustainable tourism and sustainable community development in the coastal regions which can have implication for the sustainable tourism management and community development in other context as well.

\section{Aims and Objectives}

The main aim of this research is to examine the effects of sustainable tourism on sustainable community development of the coastal regions in the UK through the perceptions of the managers of selected hotels, restaurants and travel agents. The main objectives of this study are:

- To examine the extent of sustainable tourism practices in the coastal regions in the UK.

- To explore the extent of sustainable community development in the coastal regions in the UK.

- To examine the effects of sustainable tourism practices on sustainable community development.

\section{Literature Review}

\section{Tourism: Concept and Meaning}

Generally, tourism is the temporary movement of individuals to different destinations which are outside their residence or workplace, the functions carried out during their visit in these destinations, and the resources created to fulfill their necessities. Vanhove (2005) defines tourism as the collection of services, activities and industries which provides travel experiences, containing accommodation, transportation, drinking and eating establishments, entertainment business, retail shops and other hospitality services offered to the groups or individuals travelling away from their home. It is rapidly growing and one of the greatest service oriented industries which incredibly plays important roles in improving national and international economy, speeding up competitive development of the local communities and generates range of employment opportunities for the service labour market in the world (WTTC, 2013).

According to Jenkins (1998), tourism is a highly labour intensive industry which has no tariff barriers solely based on cultural and natural resources. It has higher growth rate in comparison to international trade that provide significant revenue to many countries to gear up their economy. It has not only contributed economic growth but also contribute on peace, security and environment protection. It is considerably contributing sustainable development of various developing nations (UNWTO, 2014). As Mark (2004) asserted that tourism can also encourage global peace through the promotion of crosscultural understanding and also contributed to minimize extensive poverty globally.

\section{Sustainable Tourism}

The tourism growth in the world has brought main environment problems that needs to be addressed for the achievement of sustainability for the long-term. Environmental pollution, land degradation, deforestation, damage of species, improper waste management and inadequate utilisation of resources have resulted destruction of various natural resources or to be endangered (Muhanna, 2006). Because of natural depletion in different tourism destinations, there were various arguments to control inadequate utilisation of resources in the world (Bowman, 2011). Consequently, many international conventions, protocols and reports have been prepared by key nongovernmental and governmental bodies in order to address these crisis and offering resolutions. In this context, the concept of sustainable tourism has been emerged and become an important component of entire tourism concept (Sharpley and Telfer, 2002).

Sustainable tourism is a new dimension in the development of tourism concept which aims to diminish the adverse effects of tourism and enhance probable positive advantages for the industry to maintain economic growth, lifestyle standard, and excel other structure of development with maintaining natural resources which is very important for the host communities (Muhanna, 2006). Sustainable tourism is a way of development of overall tourism which fulfill the needs of current visitors and host 
country while conserving and enhancing natural resources for the reason of using these in the future (WTO, 1995). It aims towards the efficient management of available resources for the fulfillment of economic, social and environmental needs and maintains indispensable ecological procedures, biological diversity and cultural integrity (Sharpley, 2010). This thought further focuses that the development of tourism should be economically viable, ecologically bearable, and ethically equitable for the host areas (Holden, 2008).

Sustainable tourism is important to the communities of rural and urban regions as well as the business associated with tourism. There are clear evidences to demonstrate that any destination that reduces environmental effects is more profitable, competitive, valuable and more sustainable (Hardy \& Beeton, 2001). Therefore, sustainable tourism is essential for the long-term sustainability of the tourism sector and whole industry which ensures that it maintains the overall quality of local communities and the quality of visitor experiences. According to Hall \& Richards (2000), the objectives of such tourism concept is to retain the social and economic advantages of the development of tourism while reducing any unwanted effects on historic, natural, social or cultural environments.

According to Slaper and Hall (2011), sustainable tourism has three key components that are sometimes referred to as the 'triple bottom line' which are environmentally, socially and culturally, and economically. It has low effects on natural resources especially in protected regions. It also reduces damage to the ecological atmosphere such as flora, fauna, habitats, living marine resources, water, use of energy, contamination and so on. In addition, sustainable tourism does not harm culture and social structure of the host community. But, it respects local traditions and cultures which also involve most of the stakeholders in every stage of planning, developing, and monitoring and educate them about their responsibilities. Finally, it helps the communities and other stakeholders to be well being, and helps to generate equitable and sustainable income (Farrell \& Twining-Ward, 2004).

One of the important principles of sustainable tourism is ecological sustainability that refers to the execution of development which is well-suited to the preservation of biological diversity, ecological process and natural resources (Pulido \& Sa'nchez, 2009). Because of significant dependence of tourism on natural environment preserving the tourism destination attractions and its natural assets play important roles to tourism growth and enhance the destination popularity. Appropriate tourism planning of a destination can be capable to preserve environment, support economically and also preserve the cultural heritage of the place. Conversely, if the tourism planning is not appropriate, it can destroy vegetation, pollute beaches, create overcrowding, ignore local interests and eliminate open space (Muhanna, 2006). Thus, tourismthe largest industry in the world should provide safe and healthy environment for the visitors, should preserve natural and cultural environment, and should also provide opportunities for the local communities.

\section{Dimensions of Sustainable Tourism}

Sustainable tourism is a form of modern tourism concept which helps to satisfy the needs and expectations of the current tourists and host area with developing and preserving natural resources for the purpose of future use (Padin, 2012). It seeks to warrant best management of available natural and other resources for the aim of fulfilling economic, social and aesthetic needs and maintain natural ecosystem, biological diversity, and cultural integrity (Liu, 2003).

A lot of earlier researchers have examined tourism activities with single aspects of tourism such as the economic effects of tourism generally examined by using the number of arrivals, average length of stay, receipt per tourists and other economic indicators (Ekins et al., 2003). Some scholars have concentrated on the use of resources such as cultural and natural resources. However, dealing with sustainability measurement is highly growing in the recent decades (Bowman, 2011). In this regard Miller (2000) presented many indicators that cover various aspects of sustainability: employment issue for the local community, environmental issues for physical and human beings, financial and customers' prospects such as level of satisfaction.

Similarly, there was another attempt by Ko (2005) to create a comparative methodology to examine sustainable tourism. He argues after reviewing existing literature that "methods of systematic sustainability assessment are not currently used in tourism" (p. 4). He added that most of the earlier researchers in this field are descriptive which are based on qualitative data and conclusions are based on subjective process, it is therefore there is a lack in rigorous methodology to analyse sustainability issue in the sector of tourism. He has thus developed a tourism sustainability assessment framework based on eight parameters: economic, political, socio-cultural, environmental impacts, production related aspects, ecosystem quality, environmental politics and biodiversity.

\section{Economic Sustainability}

This factor consists of tourism assets, tourism activity, linkages such as tourism revenue for all economy and leakages such as missed opportunity. The tourism assets are very important factor which motivate tourism in selecting a particular destination (Leisen, 2001). Therefore, the tourism assets need to be carefully examined prior to make decision of expanding or development of tourism in the particular area. The 
evaluation of tourism assets can further assists to select and develop fitting tourism activities in the particular destination that can have vital role in the development of sustainable tourism (Sharply, 2010).

It is also significant to examine how the country exploits the tourism assets or what are the tourism activities in the destination. The tourism assets can be examined by revenue and number of tourists visits the particular destination (Leisen, 2001). One of the important means to increase economic advantages of tourism is to integrate tourism into national economy through the establishment of linkage in between tourism activity and other sectors of the economy such as fisheries, agriculture, and construction. When the tourism sectoruses the services and products produced within the local economy that can help to strengthen these sectors (Padin, 2012).

If there is no linkage between the tourism and other sectors of the domestic economy then an important part of development potential will be lost. Leakages are generally defined as the loss of hidden costs and foreign exchange deriving from tourism functions. The leakage can include two major elements: internal leakage and external leakage. The internal leakage is the loss because of tourism functions which refers to the proportion of imported goods needed to provide the service or 'import coefficient' of tourism (Cernat \& Gourdon, 2007). Similarly, the external leakage is the opportunity costs which are originated outside the economic space of the tourism activities and this is not accounted for domestically.

\section{Socio-Ecological Sustainability}

Socio-ecological system includes social or human beings and ecological or biophysical subsystem in mutual interactions (Gallopin, 2006). The social factor qualifies the attachment of local communities in different activities of tourism. The environmental aspects include the implementation of quality and environmental standards agreed by important international organisations for the projects of tourism and allocation of tourism revenue to prevent natural resources degradation in the country of destination (Pulido \& Sa'nchez, 2009). The main two elements of this dimension are evidently associated with the leakage and linkages issues and required to be examined together. For example, although the tourism activities can have a low leakage effect, which does not necessarily, mean that the local community will draw any advantages for these activities if local tourism related companies do not generate jobs for local people or if the pay rate is very low. Therefore, socio-ecological sustainability emphasises on the involvement of local people in different tourism functions mainly on preservation of local culture, conservation of natural environment and production of tourism services and goods in the host regions (Dredge, 2004). In addition, it also focuses on equal distribution of revenues from the tourism to local community in order to preserve degradation of resources in the destination.

\section{Infrastructural Sustainability}

Various infrastructure of the destination are considered as the important tourism assets. General infrastructures are the main focus to sustainable tourism because the convenience to particular tourism asset depends upon the overall infrastructural quality. Moreover, unlike cultural and natural resources, the infrastructure depends more on other policies rather than the promotional strategies for tourism alone. Therefore, the construction of basic infrastructure such as communication, transportation, accommodations, electricity, leisure centres and tourism parks are crucial to enhance sustainable tourism (Ritchie \& Crouch, 2000). In addition, according to Cernat \& Gourdon (2007), the main indicators of tourism infrastructures are transportation, electricity and the access of clean water, communication such as mobile phone penetration, phone lines and internet hosts.

\section{Attractiveness Sustainability}

Attractiveness sustainability is price competitiveness which is considered to be a main component playing leading roles in the selection of destination for various tourists and strengthens the competitiveness of the destination. The competitiveness also depends upon attitudes of the local people, hospitality, and security of the destination place. It is thus, these elements to be more competitive than other factors so that the destination can achieve more benefits from the tourism and develops sustainability of the destination (Pulido \& Sa'nchez, 2009). Therefore, the indicators of attractiveness sustainability are price competiveness such as a mix of purchasing power parity index and the hotel price index, and the index on human resources which is based on educational index (Cernat \& Gourdon, 2007).

\section{Site-Design Sustainability}

Site design of the destination is also an important concept of sustainable tourism. The design is the process of creation and problem solving which goes beyond spatial planning, sculptural appearance and form in development context. So, it is a cyclical procedure which enables resolutions to be developed to complex social, environmental, cultural and economic issues (South Australian Tourism Commission, 2007). The cyclical design procedure allows continual learning and enhancing knowledge and finding the solution which best fits the social, environmental and economic requirements. The good design result of the site is if the created environment becomes an ecologically incorporated part of the wider environments. While working on the development of tourism in the natural areas requires a broad knowledge 
initially from different disciplines and stakeholders perspectives to be taken into the process of design.

\section{Sustainable Community Development}

The concept of sustainable development was first traced back when the needs of conservation of the natural environment was realised in the history at around 1970s. According to International Institute for Sustainable Development IISD (2014), sustainable development is the concept of development procedure which meets the needs of present without negotiating the capability of upcoming generations to fulfill their necessities. It involves the two major concepts: the concept of needs and the idea of limitations. The concept of needs is linked to the specific needs of the poor communities in the world to which main priority should be provided; and the concept of limitations impose the state of technology as well as social institutions on the capability of the environment to meet current and future needs (Ny et al., 2006). The development process needs consideration and transformation in the direction of the imperatives of sustainability in which the development of the community if no exception. Sustainability indicates the capability of human community to continue within the limited natural resources and its underlying cycle of nature (James \& Lahti, 2004). In addition, sustainable development has been defined on the basis of development which is economically viable, socially just, culturally and ethically conscious, institutionally effective and environmentally appropriate (Shaffer et al., 2006).

Sustainable community development is an approach of development that includes the development activities which meets the needs and wants of individuals living in the local community without obstructing the needs of future generation to fulfill their own needs in long-run ( $\mathrm{Ny}$ et al., 2006). It is a continuing procedure that aims to ensure long-run economic prosperity, social equity, minimise excessive use of resources, maintain diversity, conserve heritages, and encourage community participation. Sustainable community development in addition is a systematic procedure of warranting better life quality of the t people in the community at present and for upcoming generations (Shaffer et al., 2006). Moreover, sustainable community development is a thought of achieving effective environmental protection, social development, efficient use of natural resources, maintaining high level of employment opportunities for the local communities, and economic growth (Muhanna, 2006).

\section{Components of Sustainable Community Development}

Different scholars proposed different measures for sustainable community development. The major factors for sustainable community development can be consumption of energy, transportation and diet. If we consider these three factors, it can make easy to see how diminution in fossil fuel are tied to them. The taxes in transportation are very high in fossil fuels than anything else, but it is trailed intimately by cooling, heating and electric uses. The diets related to the products from agriculture in the grocery store (Elhaut, 2007).
The three dimensions of sustainable development: economic growth, social inclusion and environmental balance which are developed in the second half of the 1980s (Sharply, 2010). These three pillars of sustainability are strong tool for discussion entire sustainability issues. If one pillar out of three is week then the system of sustainable development can be unsustainable.

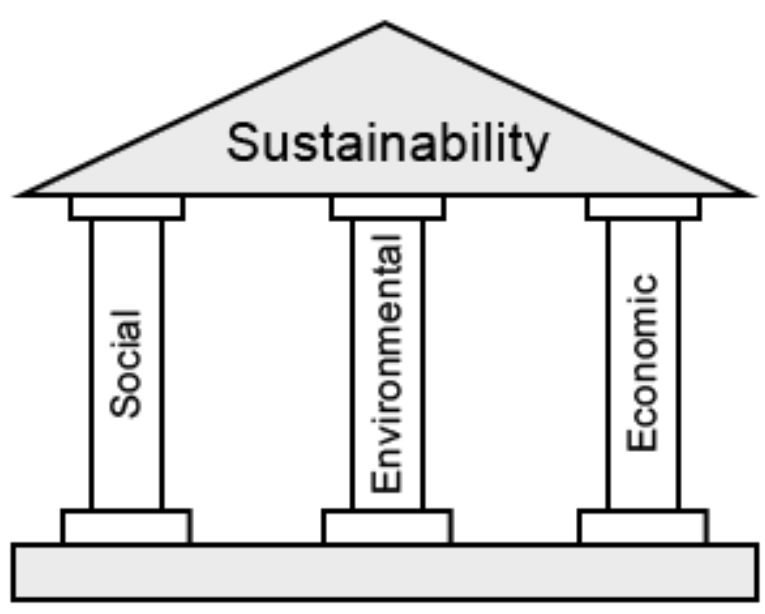

Fig. 1: Three Pillars of Sustainability

These three factors are used to assess the extent of sustainable community development in Southend-on-Sea in this research.

\section{Prosperous Economy}

The backbone for sustainable development is economy of the place which needs to be prosperous and capable to generate investments and wealth for long-term in local society without ruining natural and social capital in which entire economy rely; minimise environmental effects and use of resources; develops new skills through training and development; meets basic needs by providing employments for the local communities (Kates et al., 2005). It is therefore, prosperous economy focuses on rational and systematic allocation of resources for efficient produce of goods and service in long-run, and act of maintaining stability in between government income and expenditures (Harris \& Goodwin, 2001). Hence, community members are intended to invest their capital which will preserve local and natural resources and generate suitable returns on investments in association of building powerful pillar for sustainable community development.

\section{Social Wellbeing}

The concept of social well being equally strains on the achievements of social well-being and social-welfare which concentrates on equal distribution of advantages, availability of education, food, shelter, health, security, income and working situation eventually for all (Kates et 
al., 2005). Therefore, sustainable community development is the covering principles to address current alarming problems of inequality, poverty, hunger, climate change, and other forms environmental and human disasters (Harris \& Goodwin, 2001). Thus, sustainable community development advocates resources conservation, autonomous and self motivated participation of all stakeholders, social and economic respect and justice for all lives.

\section{Ecology and Environment}

The pillar of ecology and environment concept focuses on efficient management and conservation of natural resources and maintenance of ecosystem, atmospheric and biodiversity of the planet or the particular tourism destination (Harris, 2000). Therefore, environmental sustainability includes minimal waste or pollution, maximum protection of the environment and minimum ecological impacts, focusing on recycling, and increasing biodiversity, wildlife and natural environment which should ensure the all present and future generations can ultimately enjoy the benefits from the environment (Kates et al., 2005).Thus, management and maintenance of ecology and environment is an important pillar of sustainable community development and so various companies operating to the destination should mainly focus on reducing the effects of their activities on natural resources and protecting environment for realising sustainable community development.

\section{Research Frameworkand Hypotheses}

The following research framework is developed from the above literature review:

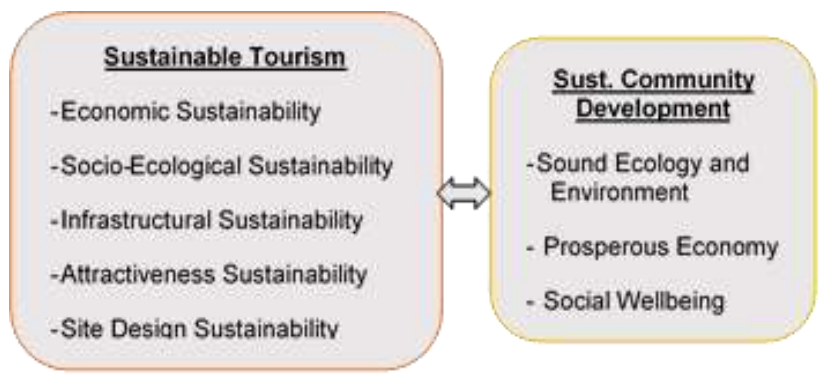

Fig. 2: Research Framework

The following hypotheses are generated in this study.

H1: There is a high level of sustainable tourism practices in the coastal regions in the UK.

H2: There is high level of sustainable community development practices in the coastal regions in the UK.

H3: Sustainable tourism practicehas significant positive impacts on sustainable community development of the destination.

\section{Research Methodology}

\section{Research Approach}

This study has used deductive approach in which a survey was conducted in order to test the hypotheses and making conclusion of the investigation. The deductive approach is used here because it is more time saving and it can be more effective for quantitative studies. Thus, the reasoning of this study is started with the existing knowledge about sustainable tourism and sustainable community development and hypotheses are formed with the help of existing theories and literature.

\section{Research Strategy}

A strategy of survey was used in this research for the collection of primary data from the participants. This strategy follows scientific process and orders and quantitative facts are collected regarding social activities, aspects, compositions, their beliefs and so on (Sekaran \& Bougie, 2010). The main benefits of survey are: it can be less complicated to execute and useful for gaining much data from more number of respondents in highly economic way. However, it may not provide cause-and-effects relationship, and can have very low level of response rate. The strategy of survey is chosen in the sense that it is an easy way for quantitative data collection and analysis using descriptive and inferential statistics. It can provide valid, genuine and accurate data from the participants. This investigation followed questionnaires survey in which a set of questionnaires is prepared and used to collect primary data from the respondents associated to tourism development and community development at Southendon-Sea region UK.

\section{Data Collection}

The questionnaires survey was used to collect primary data from the participants, which provides data in quantitative form that can be easily analysed by using statistical and mathematical tools and models. The questionnaires method is adopted because it is more practical than other methods; large amount of data can be gathered in short time with relatively low costs, the result from the questionnaires can easily be analysed using available software such as SPSS, and can be examined more objectively and scientifically than obtained from other processes (Neupane, 2012).

The questionnaires were formed by considering the main components of sustainable tourism: economic sustainability, socio-ecological sustainability, infrastructural sustainability, attractiveness sustainability, transportation sustainability, and site design sustainability which are identifies in the literature review. Similarly, the main three components of sustainable community development: sound ecology and environment, prosperous economy and social wellbeing are used while forming 
questionnaires to examine sustainable community development. The questionnaires is closed ended and contains multiple choice and in the rating scale.The managers of each selected entity are informed about the purpose of data collection and a set of questionnaire are distributed to each entity and collected next day after answering the questionnaires.

\section{Sampling and Sample Size}

The convenience sampling technique is applied here because the population in this research is not homogeneous but it is heterogeneous. This method is appropriate in this case because it can be used on the basis of individual judgement of the researcher and which is appropriate in this research. Therefore, the researcher has used his individual judgement which is easily accessible while selecting a sample from the population. The list of hotels in Booking.com website, restaurants listed in TripAdvisor UK website, travel agencies and local council offices are selected to collect data in this research. The senior managers or each entity is asked to fill the questionnaires of this survey.

The set of 250 questionnaires were distributed to the participants including hotels, restaurants, travel agents, and local council officeand asked to answer within one week time in Southend-on-Sea. Form each entity of hotel, restaurants and travel agents, local councils only one senior manager is chosen to answer the questionnaires as considering the fact that the sustainable tourism practice can be understood by the managers rather than junior employees. Out of 250 questionnaires distributed, the researcher obtained 160 appropriately answered questionnaires and that is used in the research process.

\section{Data Analysis Process}

The collected data in this questionnaires survey are in quantitative nature and so it has followed quantitative data analysis techniques. The collected data are entered in to Statistical Package for Social Science (SPSS 20) after providing appropriate codes for each variable considered in the questionnaires. Then, the data are analysed by using different charts, arithmetic mean, standard deviation, correlation and regression between the variables. Particularly, the relationships between sustainable tourism and sustainable community development are assessed through correlation and regression analysis. The extent of sustainable tourism practices in Southend-on-Sea is examined by using arithmetic mean and standard deviation of the scores obtained in the rating scale for the factored of sustainable tourism. Similarly, the extent of sustainable community development in Southend-on-Sea is also analysed with mean and standard deviation of the scores obtained in the rating scale for the factors of sustainable community development.

\section{Data Analysis, Findings and Discussion}

\section{Distribution of Category of Participated Organisations}

The following table 4.1 shows the participants of different organisation in the survey.

Table 1: Category of Participated Organisations

\begin{tabular}{|l|l|l|}
\hline Category & Frequency & Percentage \\
\hline Hotels & 60 & $37.5 \%$ \\
\hline Restaurants & 56 & $35.0 \%$ \\
\hline Travel Agents & 34 & $21.3 \%$ \\
\hline Others & 10 & $6.25 \%$ \\
\hline Total & 160 & $100 \%$ \\
\hline
\end{tabular}

The table shows that the highest numbers of participants are from restaurant category and the lowest numbers of participants are from others category which includes local council office. The percentages of respective categories are shown in the following diagram.

\section{Category of Participated Organisations}

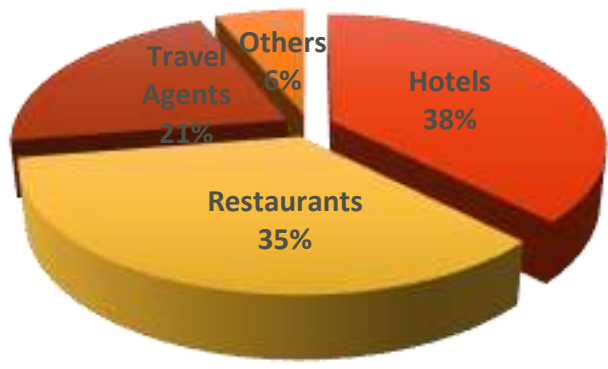

Fig. 3: Category of Participated Organisations

The above pie chart shows that the percentage of hotel is the highest among other categories which is about $38 \%$ of the total, and the percentage of other category is $6 \%$ which is the lowest among other categories. Similarly, the percentage of restaurant is $35 \%$ which is slightly lower than the percentage of hotels, and the percentage of travel agents participated in the survey is $21 \%$ of the total participation.

\section{Evaluation of Sustainable Tourism Practices in the Coastal Regions}

The extent of sustainable tourism practices in the UK coastal regions is analysed by computing mean of the scores obtained in the likert scale for the variables of sustainable tourism practices. In the likert scale, 1 represents strongly disagree, 3 represents average and 5 represents strongly agree. The following table 4.2 shows the mean and standard deviation (SD) of the scores of the parameters of sustainable tourism practices. 
Table 2: Mean and SD of the Scores for Sustainable Tourism Variables

\begin{tabular}{|l|l|l|}
\hline Variables & Mean & SD \\
\hline Economic Sustainability & 4.27 & 0.304 \\
\hline Socio-Ecological Sustainability & 4.18 & 0.400 \\
\hline Infrastructural Sustainability & 4.25 & 0.324 \\
\hline Attractiveness Sustainability & 4.17 & 0.390 \\
\hline Site-Design Sustainability & 4.08 & 0.411 \\
\hline Overall Sustainable Tourism & 4.19 & 0.255 \\
\hline
\end{tabular}

The above table shows that all the factors of sustainable tourism have mean score more than 4.08 out of 5 in which 1 refers strongly disagree, 3 refers neutral, and 5 refers strongly agree. The highest value of mean score is 4.27 obtained from economic sustainability, and the smallest value of mean score is 4.08 obtained from site-design sustainability. Similarly, the mean score of socioecological sustainability is 4.18 , mean of infrastructural sustainability is 4.25 , mean of attractiveness sustainability is 4.08 and mean of overall sustainable tourism is 4.19 out of five. Thus, mean score for all the variables of sustainable tourism more than average level three indicates that there is high level of sustainable tourism practices in the coastal regions in the UK.

The standard deviation of the scores for the factors of sustainable tourism practices obtained in the likert scale is ranged in between 0.255 and 0.400 . The SD of economic sustainability is 0.30 , socio ecological sustainability is 0.400 , infrastructural sustainability is 0.323 , attractiveness sustainability is 0.390 , site-design sustainability is 0.411 , and SD of overall sustainable tourism is 0.255 . This indicates that there is no high variation of the scores obtained in the likert scale for the factors of sustainable tourism practices in the coastal regions in the UK.

Thus, the above analysis shows that mean score for each variable of sustainable tourism practices is more than 4.08 out of five and which is more than $81.6 \%$. Similarly, the mean score of overall sustainable tourism is 4.19 out of 5 which is about $83.8 \%$ indicates that there is a high level of sustainable tourism practices in the coastal regions in the UK.

\section{Evaluation of Sustainable Community Development in the Coastal Regions}

The sustainable community development in the UK coastal regions is also analysed by using arithmetic mean and standard deviations of the scores obtained in the likert scale for the factors of sustainable community development. The mean and standard deviations of the scores for the variables of sustainable community development is shown in the following table 4.4
Table 3: Mean and SD of the Scores for the Variables of Sustainable Community Development

\begin{tabular}{|l|l|l|}
\hline Variables & Mean & SD \\
\hline Prosperous Economy & 4.05 & 0.324 \\
\hline Social Wellbeing & 4.16 & 0.326 \\
\hline Ecology and Environment & 4.12 & 0.314 \\
\hline $\begin{array}{l}\text { Overall Sustainable Community } \\
\text { Development }\end{array}$ & 4.11 & 0.270 \\
\hline
\end{tabular}

The mean scores for all the variables of sustainable community development are all more than 4.05 out of 5 in which 1 refers strongly disagree, 3 refers neutral, and 5 refers strongly agree. The highest value of mean score is 4.16 which is obtained from social wellbeing factor and the smallest mean score is 4.05 which is obtained from prosperous economy. Similarly, the mean score of ecology and environment is 4.12 , and finally the overall mean score of sustainable community development is 4.11 out of 5. This means that there is highest level of sustainable community development practice in social wellbeing factor and the lowest practice in prosperous economy.

The standard deviation of the scores for the factors of sustainable community development is ranged in between 0.270 to 0.325 . The highest value of SD is 0.325 which is from social wellbeing and the smallest value of SD is 0.270 from overall sustainable community development. Similarly, the SD of prosperous economy is 0.324 , and SD of ecology and environment is 0.314 . These values of SD show that there is no high variation of the scores obtained in the likert scale for the variables of sustainable community development.

Thus, the above analysis shows that all the variables of sustainable community development have mean scores more than 4.05 which is more than neutral level 3 , out of 5. The mean score for overall sustainable community development is 4.11 out of five which is $82.2 \%$ indicates that there is a high level of sustainable community development in the coastal regions in the UK.

\section{Analysis of the Effects of Sustainable Tourism Practices on Sustainable Community Development}

The effects of sustainable tourism practices on sustainable community development is analysed by using correlation and regression analysis between the factors of sustainable tourism and sustainable community development.

\section{Correlation Analysis}

The correlation coefficient (r) between the factors of sustainable tourism and sustainable community development are computed through SPSS and shown below: The correlation coefficients are computed in order to analyse the relationships between the variables of sustainable tourism and the variables of sustainable community development. 
Table 4: Correlations between The factors of Sustainable Tourism and Sustainable Community Development

\begin{tabular}{|c|c|c|c|c|c|c|c|c|c|c|}
\hline & 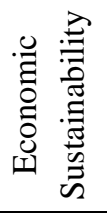 & 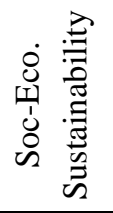 & 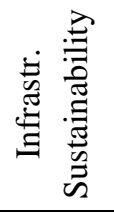 & 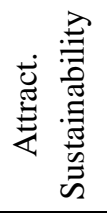 & 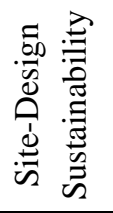 & $\begin{array}{l}\forall \\
\dot{n} \\
\bar{\Xi} \\
\overrightarrow{0} \\
\overrightarrow{0}\end{array}$ & $\begin{array}{l}0 \\
0 \\
0 \\
0 \\
0 \\
0 \\
0 \\
0 \\
0 \\
0 \\
0 \\
0\end{array}$ & 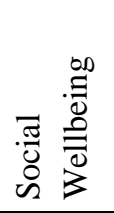 & 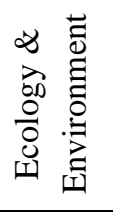 & $\begin{array}{ll}\overline{\bar{J}} & 0 \\
0 & 0 \\
0 & \dot{0}\end{array}$ \\
\hline Economic Sustainability & 1 & & & & & & & & & \\
\hline Socio-Eco. Sustainability & $.377^{*}$ & 1 & & & & & & & & \\
\hline $\begin{array}{l}\text { Infrastructural } \\
\text { Sustainability }\end{array}$ & $.680^{* *}$ & $.781^{* *}$ & 1 & & & & & & & \\
\hline $\begin{array}{l}\text { Attractiveness } \\
\text { Sustainability }\end{array}$ & $.369^{*}$ & $.436^{* *}$ & $.395^{*}$ & 1 & & & & & & \\
\hline Site-Design Sustainability & .176 & .105 & .251 & .166 & 1 & & & & & \\
\hline Overall ST & $.698^{* *}$ & $.769^{* *}$ & $.862^{* *}$ & $.684^{* *}$ & $.511^{* * *}$ & 1 & & & & \\
\hline Prosperous Economy & $.468^{* *}$ & $.516^{* *}$ & $.577^{* *}$ & $.514^{* *}$ & .272 & $.664^{* * *}$ & 1 & & & \\
\hline Social Wellbeing & $.445^{* *}$ & $.731^{* *}$ & $.570^{* *}$ & $.446^{* *}$ & $.409^{*}$ & $.748^{* * *}$ & $.574^{* * *}$ & 1 & & \\
\hline Ecology \& Environment & $.658^{* *}$ & $.349^{*}$ & $.512^{* *}$ & .081 & $.603^{* *}$ & $.615^{* *}$ & $.465^{* *}$ & $.642^{* *}$ & 1 & \\
\hline Overall SCD & $.621^{* *}$ & $.635^{* *}$ & $.658^{* *}$ & $.416^{* *}$ & $.506^{* *}$ & $.804^{* *}$ & $.811^{* * *}$ & $.880^{* * *}$ & $.831^{* *}$ & 1 \\
\hline
\end{tabular}

The above correlation table shows that all the variables of sustainable tourism and all the variables of sustainable community development are positively correlated and most of the correlation coefficients are significant at 0.01 and 0.05 levels. The correlation coefficient $r$ in between economic sustainability and overall sustainable community development is 0.621 , socio-ecological sustainability and overall sustainable community development is 0.635 , infrastructural sustainability and overall sustainable community development is 0.658 , attractiveness sustainability and overall sustainable community development is 0.416 , and site design sustainability and overall sustainable community development is 0.506 which all are positive and significantly correlated at the 0.01 significant level. Similarly, the overall sustainable tourism and overall sustainable community development have correlation coefficient $r=0.804$ which is strong positive and significant at the 0.01 level. Thus, the correlation analysis indicates that sustainable tourism and sustainable community development are positively correlated with each other.

\section{Regression Analysis}

The regression between overall sustainable tourism and overall community development is computed where overall sustainable community development is dependent variable and overall sustainable tourism is independent or predictor variable. The following three tables show the model summary, ANOVA and coefficients of the regression.

Table 5: Model Summary

\begin{tabular}{|l|c|r|r|r|}
\hline Model & $\mathrm{R}$ & \multicolumn{1}{|c|}{ R Square } & \multicolumn{1}{|c|}{$\begin{array}{c}\text { Adjusted R } \\
\text { Square }\end{array}$} & $\begin{array}{c}\text { Std. Error of } \\
\text { the Estimate }\end{array}$ \\
\hline 1 & $.804^{\mathrm{a}}$ & .647 & .637 & .16285 \\
\hline
\end{tabular}

a. Predictors: (Constant), Overall Sustainable Tourism

Table 6: ANOVA

ANOVA $^{\mathrm{a}}$

\begin{tabular}{|c|c|c|c|c|c|}
\hline Model & $\begin{array}{l}\text { Sum of } \\
\text { Squares }\end{array}$ & Df & $\begin{array}{l}\text { Mean } \\
\text { Square }\end{array}$ & $\mathrm{F}$ & Sig. \\
\hline Regression & 7.613 & 1 & 7.613 & 65.954 & $.000^{\mathrm{b}}$ \\
\hline 1 Residual & 3.960 & 158 & .025 & & \\
\hline Total & 11.573 & 159 & & & \\
\hline
\end{tabular}

a. Dependent Variable: Overall Sustainable Community Development

b. Predictors: (Constant), Overall Sustainable Tourism

In the above model summary table, the value of $\mathrm{R}=0.804$ denotes the correlation coefficient ( $r$ ) between overall sustainable tourism and overall sustainable community development. The R Square value represents the level of variation in the dependent variable: overall sustainable 
community development can be explained by the predictor variable overall sustainable tourism.

The following ANOVA Table 6 shows how well the regression model fits data or predict the dependant factor overall sustainable community development.

This shows that the regression model predicts the dependent variable overall sustainable community development significantly well due to the fact that the significance value is 0.000 that is less than 0.05 , and thus there s good fit for the data.

Table 7: Coefficients

\section{Coefficients}

\begin{tabular}{|c|c|c|c|c|c|}
\hline \multirow{2}{*}{ Model } & \multicolumn{2}{|c|}{$\begin{array}{l}\text { Unstandardize } \\
\text { d Coefficients }\end{array}$} & \multirow{2}{*}{$\begin{array}{l}\text { Standardize } \\
\mathrm{d} \\
\text { Coefficient } \\
\mathrm{s}\end{array}$} & \multirow{2}{*}{$\mathrm{t}$} & \multirow{2}{*}{ Sig. } \\
\hline & B & $\begin{array}{l}\text { Std. } \\
\text { Error }\end{array}$ & & & \\
\hline $\begin{array}{l}\text { (Constant) } \\
1 \text { OverallSustainab } \\
\text { le Tourism }\end{array}$ & $\begin{array}{l}.59 \\
4 \\
.83 \\
9\end{array}$ & .202 & .804 & $\begin{array}{l}2.947 \\
17.42 \\
8\end{array}$ & $\begin{array}{l}.00 \\
4 \\
.00 \\
0\end{array}$ \\
\hline
\end{tabular}

a. Dependent Variable: OverallSustainable Community DevelopmentThe above coefficient of regression table shows the essential information to forecast sustainable community development with respect to sustainable tourism. The table shows that overall sustainable tourism has significant contribution to sustainable community development as the value of sig. $\mathrm{P}$ $=0.000$ which is $<0.05$.

The regression equation is as follows:

Sustainable community development $=0.594+0.839$ (Sustainable tourism).

Thus, the above regression analysis shows that sustainable tourism practices have significant effects on sustainable community development as $\beta=0.804$, and $\mathrm{P}=0.000$ which is less than 0.05 .

\section{Discussion of the Main Findings}

This study has analysed the effects of sustainable tourism on sustainable community development in coastal regions in the UK. The five factors of sustainable tourism and three factors of sustainable community development from the three pillars of sustainable development are used to measure the sustainable tourism and sustainable community development respectively. This study confirmed that sustainable tourism has significant positive effects on sustainable community development.

The results shows that mean score for each variable of sustainable tourism practices is more than 4.08 out of five in which the values of mean score higher than 3 are considered to be high level of agreement, and which is more than $81.6 \%$. Similarly, the mean score of overall sustainable tourism is 4.19 out of 5 which is about $83.8 \%$ indicates that there is a high level of sustainable tourism practices in the coastal regions in the UK. These results support

Hypothesis 1: There is a high level of sustainable tourism practices in the coastal regions in the UK. Therefore, $\mathrm{H} 1$ is accepted. This result is consistent with the results published by Southend-on-Sea in 2013 in their 'development plan document and development management'. The report stated that the destination is economically developed in different areas such as employment sectors, accommodations, network centres and so on; it has good level of environment in comparison to other similar destinations; and advanced transportation system and accessibility (Southend-on-Sea Borough Council, 2013).

The results on the evaluation of sustainability community development shows that all the variable of sustainable community development have mean scores more than 4.05 which is more than neutral level 3 , out of 5 . The mean score for overall sustainable community development is 4.11 out of five which is $82.2 \%$ indicates that there is a high level of sustainable community development in the coastal regions in the UK. This finding supports Hypothesis 2: There is high level of sustainable community development practices in the coastal regions in the UK. Thus, $\mathrm{H} 2$ is also accepted. This results is also consistent with the report published by Southend-on-Sea Borough Council (2014) which stated that different sustainable development policies are implemented in the destination which include efficient use of natural resources involving energy and water use, the town centre in Southend-on-Sea is focusing on employment development and the employments priorities are provided for the local people, and the policy of protecting ecology and environment of the local area is strictly implemented.

Similarly, this study asserted that sustainable tourism and sustainable community are positively and significantly correlated as all the variable of sustainable tourism and sustainable community development are positively correlated with the overall sustainable tourism and overall sustainable community development have correlation coefficient $(r)=0.804$ which strong positive and significant at the 0.01 level. Similarly, regression analysis shows that sustainable tourism has significant effects on sustainable community development as $\beta=0.804$, and $\mathrm{P}=$ 0.000 which is less than 0.05. These findings support Hypothesis 3: Sustainable tourism practice has significant positive effects on sustainable community development of the destination.These findings are consistent with the assertions of many studied in the past. As Muhanna (2006) asserted that sustainable tourism is significant for the industry to maintain economic growth, lifestyle standard, and excel other structure of development with maintaining 
natural resources which is very important for the host communities. Similarly, Sharpley (2010) claimed that sustainable tourism is important for efficient management of available resources for the fulfilment of economic, social and environmental needs and maintains indispensable ecological procedures, biological diversity and cultural integrity. Similarly, the current findings are similar to Hardy \& Beeton, (2001). They asserted that sustainable tourism is important to the communities of rural and urban regions as well as the business associated with tourism. There are clear evidences to demonstrate that any destination that reduces environmental effects is more profitable, competitive, valuable and more sustainable. Therefore, sustainable tourism is essential for the longterm sustainability of the tourism sector and whole industry which ensures that it maintains the overall quality of local communities and the quality of visitor experiences.

\section{Conclusion and Recommendations}

\section{Conclusion}

This empirical research examined the effects of sustainable tourism on sustainable community development in coastal regions in the UK. This research followed the proposition deductive approach in which the research starts with the formulation of hypotheses from the base of existing literature and theories, and the remaining research procedure is guided to test the hypotheses. So, the three hypotheses were formed with the help of existing literature in this research. The primary data collection related to sustainable tourism and sustainable community development was conducted and used to test the hypotheses.

The five factors of sustainable tourism: economic sustainability, socio-ecological sustainability, infrastructural sustainability, attractiveness sustainability, site-design sustainability; and three factors of sustainable community development are applied to assess the sustainable tourism practices and sustainable community development in the coastal regions in the UK. And, also the effects of sustainable tourism on sustainable community development is analysed by using these factors. The primary data was collected by using survey strategy using structured closed-ended questionnaires which are in five point likert scale. The data was collected from hotels, restaurants, travel agents and the local council office based on the coastal regions in the UK. The sample of 38 respondents was chosen by using convenience sampling technique or on the basis of their availability and interest. The collected data was analysed by using statistical tools and techniques such as frequency distribution, percentage, charts, mean, standard deviation, regression and correlation analysis with the help of SPSS 20.
The study confirmed that sustainable tourism has strong positive effects on sustainable community development in the context of coastal region.

The results shows that mean score for each variable of sustainable tourism practices is more than 4.08 out of 5 in which the values of mean score higher than 3 are considered to be high level of agreement, and which is more than $81.6 \%$. Similarly, the mean score of overall sustainable tourism is 4.19 out of 5 which is about $83.8 \%$ indicates that there is a high level of sustainable tourism practices in The coastal regions in the UK.

The results on the evaluation of sustainability community development shows that all the variable of sustainable community development have mean scores more than 4.05 which is more than neutral level 3 , out of 5 . The mean score for overall sustainable community development is 4.11 out of five which is $82.2 \%$ indicates that there is a high level of sustainable community development in Southend-on-Sea.

The results also indicate that sustainable tourism and sustainable development community are positively and significantly correlated as all the variable of sustainable tourism and sustainable community development are positively correlated with the overall sustainable tourism and overall sustainable community development have correlation coefficient $(r)=0.804$ which strong positive and significant at the 0.01 level. Similarly, regression analysis shows that sustainable tourism has significant effects on sustainable community development as $\beta=$ 0.804 , and $\mathrm{P}=0.000$ which is less than 0.05 .

\section{Recommendations}

This study suggested that the site-design sustainability has the lowest mean score which 4.08 out of 5 , however it is higher than neutral level 3 . This means that the site design is comparatively less effective than other factors of sustainable tourism. So, it is recommended that the concerned authority for the development of coastal regions in the UK should focus on design of the site on the basis of appropriateness of the place which can be helpful in sustainable tourism development of the destination. In addition, the authority should give priority to attractiveness of the place, socio-ecological factors and infrastructure respectively in order to further develop sustainable tourism in the coastal regions in the UK.

Next, the evaluation of sustainability community development shows that the lowest value of mean score is 4.05 obtained from prosperous economy. This means that the authority of the community development in the coastal regions in the UK should focus on economic development of the destination. The economic development can include supporting local markets and encouraging fair trade, promoting more employment opportunities for the local 
people in tourism sector, and encouraging the organisations operating their business in the local place in investing some portion of their profits to the development of the local site.

In addition, the authority for the development of coastal regions in the UK focus on efficient use of resources, energy saving programmes, and recycling of waste and as far as possible in order to maintain ecological environment of the local destination. The authority can make regulation about providing employment opportunity for the local people, should allocate some percentage of taxes in the local development and also encourage corporate social responsibility for the business companies operating in the region of Southend-on-Sea in order to further enhance sustainable community development of the local place.

\section{References}

Ali and Frew AJ (2013), Information and Communication Technologies for Sustainable Tourism. UK: Rutledge.

Ashley C (2000) Working Paper: The Impact of Tourism on Rural Livelihoods, Namibia's Experience, Overseas Development Institute, UK.

Booking.com (2015)Destinations in the United Kingdom Online available at: http://www.booking.com/country/gb.enus.html?aid=309654; label=booking-be-en-ausnzq6aPDdK\%2AlTRrs5LVuqzTQS49564843612\%3Apl\%3 Ata\%3Ap1\%3Ap2812\%2C000\%3Aac\%3Aap1t1\%3Ane g\%3Afi\%3Atikwd-

2558630230\%3Alp2524\%3Ali\%3Adec\%3Adm;sid=e7e5 c9c5b8fd7fad2282b3c1ce4a2a21;dcid=4;hide_ss $=1 \&$; ori gin $=$ disamb;srpos $=1$ [Accessed on 2015-03-12].

Bowman KS (2011) Sustainable tourism certification and state capacity: keep it local, simple, and fuzzy. International Journal of Culture, Tourism and Hospitality Research 5(3): $269-281$.

Bryman A and Bell E (2011) Business ResearchMethods. (3rd ed.). Oxford: Oxford University Press.

Cernat L \& Gourdon G (2007) Is the Concept of Sustainable Tourism Sustainable? Developing the Sustainable Tourism Benchmarking Tool. United NationsNew York and Geneva. Available at: http://unctad.org/en/docs/ditctncd20065_en.pdf [Accessed on 2015-03-15].

Dredge D (2004) Development, economy and culture: cultural heritage tourism planning, LiangZhu, China. Asia Pacific Journal of Tourism Research 9 (4): 405-422.

Ekins P, Simon S, Deutsch L, Folke C and De Groot R (2003) A framework for the practical application of the concepts of critical natural capital and strong sustainability. Ecological Economics, 44 (2-3): 165-185.

Elhaut T (2007) Sustainability, the 'via crucis' of poverty reduction: More questions than answers. Presentation made to the annual World Bank/IFAD South-Asia Partnership Review, Bangkok, Thailand, 12 November.
Epler WM and Halpenny E (2001) 'Ecotourism certification and evaluation: progress and prospects' in: Font, $\mathrm{X}$. and Buckley, R. (eds.), Ecolabels in tourism: certification and promotion of sustainable management, $\mathrm{CAB}$ International, Wallingford, UK.

Farrell B and Twining-Ward L (2004) Reconceptualising Tourism.Annals of Tourism Research, 31(2): 274-295.

Gallopin GC (2006) Linkages between vulnerability, resilience, and adaptive capacity. Global Environmental Change,16: 293-303.

Goeldner CR\& Ritchie JR (2003) Tourism Principles, Practices, Philosophies. UK: Wiley \& Sons Publishing.

Hall D and Richards G (2000) Tourism and Sustainable Community Development. London: Rutledge.

Hardy AL and Beeton RJS (2001) Sustainable tourism as maintainable tourism: Managing resources for more than average outcomes. Journal of Sustainable Tourism, 9(3): 168-192.

Harris JM (2000) Basic Principles of Sustainable Development. Global Development and Environment Institute Working Paper 00-04, online available at: http://ase.tufts.edu/gdae/publications/working_papers/Sus tainable\%20Development.PDF [Accessed on 2015-03$12]$.

Harris JM and Goodwin NR (2001) Survey of Sustainable Development: Social and economic Dimension. Washington: IslandPress.

Holden A (2008) Environment and Tourism. London: Routledge.

International Institute for Sustainable Development IISD (2014), "What is Sustainable Development? Online available at: https://www.iisd.org/sd/ [Accessed 2015-04-02].

James S and Lahti T (2004) The natural step for communities: How cities and towns can change to sustainable practices. Gabriola Island, BC, Canada: New Society Publishers.

Jenkins L (1998) Tourism in Developing Countries: The Privatization Issue. Tourism: The state of Art, ed.3: 3-9.

Kates RW, Thomas M, Parris TM, Anthony A and Leiserowitz AA (2005)What is Sustainable Development: Goals, Indicators, Values and Practice. Environment: Science and Policy for Sustainable Development, 47(3): 8-21.

Ko TG (2005) Development of a tourism sustainability assessment procedure: a conceptual approach. Tourism Management, 26 (3) :431-445.

Leisen B (2001) Image segmentation: the case of tourism destination. The Journal of Services Marketing, 15: 4966.

Liu Z (2003) Sustainable tourism development: a critique. Journal of Sustainable Tourism 11(6): 459-75.

Muhanna E (2006) Sustainable Tourism Development and Environment Management for Developing Countries. Problems and Perspectives in Management 4 (2): 14-30. 
Neupane R (2012) Effect of Relationship Marketing on Customer Satisfaction: A Case Study of Tesco. Unpublished Master's thesis. London: Coventry University.

Ny H, MacDonald JP, Broman G, Yamamoto R, and Robèrt KH (2006) Sustainability constraints as system boundaries. Journal of Industrial Ecology, 10: 61-77.

Padin C (2012) A sustainable tourism planning model: components and relationships.European Business Review, 24(6): $510-518$

Pulido JI and Sánchez M (2009) Measuring tourism sustainability: proposal of a composite index. Tourism Economics, 15(2): 277-96.

Ritchie JRB and Crouch GI (2000) The competitive destination: a sustainability perspective.Tourism Management, 2 (1): 17.

Sekaran U and Bougie R (2010) ResearchMethods for Business: A Skill Building Approach. UK: John Willey \& Sons Ltd.

Shaffer R, Deller S and Marcouiller D (2006) Rethinking community economic development. Economic Development Quarterly, 20: 59-74.

Sharpley R and Telfer D (2002) Tourism and Development: Concepts and issues. Clevedon: Channel View Publications.

Sharply R (2010) Tourism and Sustainable Development: Exploring the Theoretical Divide. Journal of Sustainable Tourism, 8(1): 1-19.

Slaper TF and Hall TJ (2011) The Triple Bottom Line: What is it and How does it work? Online available at: http://www.ibrc.indiana.edu/ibr/2011/spring/article2.html [Accessed 2015-04-25].

Southend-on-Sea Borough Council (2013) Annual Monitoring Report 2013, Pdf online available at: http://www.southend.gov.uk/downloads/file/2894/annual _monitoring_report_2013_ldfpdf[Accessed on 2015-03$15]$

Southend-on-Sea Borough Council (2014) Southend-on-Sea Development management Development Plan: Sustainability Appraisal of the Revised Proposed Submission. Pdf online at: http://www.southend.gov.uk/downloads/file/2484/sustain ability_appraisal_revised_dmdpd_march_2014 [Accessed on 2015-03-15].

Tripadvisor (2015) Best Restaurants. Online available at: http://www.tripadvisor.co.uk/Restaurants[Accessed on 2015-02-10].

UNWTO (2014) International tourism on track to end 2014 with record numbers. Online available at: http://media.unwto.org/press-release/2014-1218/international-tourism-track-end-2014-record-numbers [Accessed on 2015-03-12].

Vanhove N (2005) The economise of tourism destinations. Oxford: Elsevier Butterworth-Heinemann.

World Travel and Tourism Council (WTTC) (2013) Travel \& Tourism Economic Impact 2013 Sub Saharan Africa. London, UK: WTTC. 